to drill a pilot hole from the medial entry point to the lateral exit point. A post-operative CT scan was performed to determine successful placement of the screw within the humeral condyle and to assess:

- Distance of achieved entry and exit points from the planned entry and exit points

- Angular deviation from planned screw axis

\section{RESULTS}

All screws were completely within the humeral condyle. Mean distance between the planned entry point and the achieved entry point was $0.58 \mathrm{~mm}$ cranially and $1.26 \mathrm{~mm}$ distally. Mean distance between the planned exit point and the achieved exit point was $-0.02 \mathrm{~mm}$ cranially and $0.51 \mathrm{~mm}$ distally. Mean maximum screw angular deviation was $5.7^{\circ}$.

\section{STATEMENT (CONCLUSIONS)}

Use of CT planning and a C-guide allowed the accurate placement of transcondylar screws from medial to lateral via a medial surgical approach.

\section{Outcome's and complication's associated with standard elbow arthrodesis}

\section{Brian Crowley, Noel Fitzpatrick}

Fitzpatrick Referrals, Godalming, United Kingdom

\section{OBJECTIVES}

To report the surgical management of end stage developmental disease (DJD) by arthrodesis following failure of previous surgical intervention.

\section{METHODS}

Retrospective case series from historical clinical records. Data collected included signalment, primary surgical technique, mode of failure, revision surgical technique, preoperative and postoperative radiographic findings, complications, owner assessment and veterinary assessment.

\section{RESULTS}

23 elbows from 21 dogs were included, bodyweight range $1.9 \mathrm{~kg}-48.9 \mathrm{~kg}$. All surgeries performed in the same centre by 5 different surgeons. All elbows were considered end stage due to failure of joint replacement, congenital/traumatic malformations and progression of aggressive osteoarthritis (OA). All elbows underwent arthrodesis as a salvage procedure. 13 complications occurred in 10 elbows (43.5\%) including surgical site infection (SSI), seroma, screw breakage, plate removal and amputation. Outcome data was available for all 22 elbows. An excellent outcome was seen in 3 (13.6\%) elbows, good in 10 (45.5\%) elbows, acceptable in 7 $(31.8 \%)$ elbows and unacceptable in $2(9.1 \%)$ elbows.

\section{STATEMENT (CONCLUSIONS)}

Persistent lameness and pain associated with treating advanced elbow DJD by joint resurfacing/replacement surgery in an attempt to salvage limb function is an ongoing putative challenge. Surgical revision by elbow arthrodesis, while technically challenging may show potential in regaining or improving limb function and may contribute to overall improvement in reported quality of life.

\title{
Measuring the impact of regenerative medicine (RM) on chronic degenerative conditions in dogs, using a validated owner-reported outcome measure
}

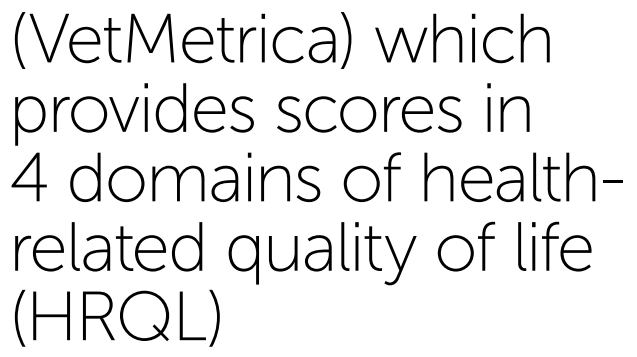

Andrew Armitage ${ }^{1}$, Jacky Reid ${ }^{2,3}$

1 Greenside Veterinary Practice, St Boswells, United Kingdom

NewMetrica Ltd, Glasgow, United Kingdom

University of Glasgow, Glasgow, United Kingdom 